\title{
Safety and efficacy of percutaneous nephrolithotomy in
}

\section{patients with a single functioning kidney compared to}

\section{patients with bilateral functioning kidneys [version 1; peer}

\section{review: 2 approved with reservations]}

\author{
Riyadh R. Al-Toma(D1,2 \\ ${ }^{1}$ Department of Surgery, College of Medicine, Karbala University, Karbala, Karbala, Iraq \\ ${ }^{2}$ Department Surgery, Safeer Al-Imam Al-Hussein Hospital, Karbala, Karbala, Iraq
}

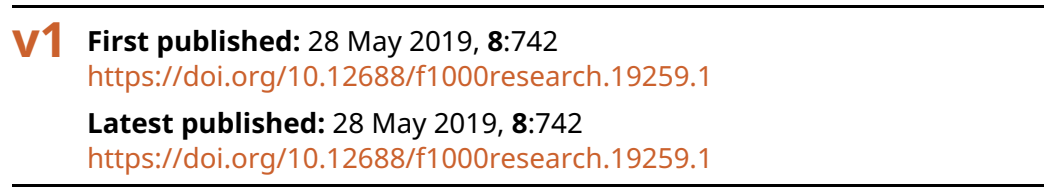

\section{Abstract}

Background: Renal stones for patients with a single functioning kidney are considered a great challenge for urologists. Different treatment modalities are used for those with a single functioning kidney, including shock wave lithotripsy, retrograde intra-renal surgery and percutaneous nephrolithotomy (PCNL). This study aimed to compare the effectiveness and safety outcomes of PCNL in patients with a single kidney compared to those with bilateral kidneys.

Methods: A prospective comparative study conducted in Urology department of Safeer Al-Imam Al-Hussein hospital in Karbala city-Iraq through the period from $1^{\text {st }}$ of March, 2015 to $30^{\text {th }}$ of September, 2018 on sample of 173 patients with renal stones surgically operated with PCNL categorized into two groups; group I included 51 patients with a single functioning kidney and group II included 122 patients with bilateral functioning kidneys.

Results: The mean age of group I patients was 42.76 years which was significantly higher than mean age of group II patients of 36.54 years $(p=0.01)$. No significant differences were observed between group I and group II patients regarding gender, pre and intraoperative characteristics. Postoperative stone clearance, bleeding, renal function, organ injury and sepsis were not significantly different between two.

Conclusions: PCNL is effective and safe surgical procedure for treatment of renal stones of patients with a single functioning kidney.

Keywords

Renal stone, Single functioning kidney, Bilateral functioning kidneys, Percutaneous nephrolithotomy, Karbala

\begin{tabular}{llc} 
Open Peer Review & \\
\hline Approval Status ? ? & 1 \\
\hline & & 2 \\
version 1 & $?$ & $?$ \\
28 May 2019 & view & view
\end{tabular}

1. Panagiotis Kallidonis, University of Patras,

Patras, Greece

2. Biagio Barone ID, University of Naples,

Naples, Italy

Luigi Napolitano, University of Naples,

Naples, Italy

Any reports and responses or comments on the article can be found at the end of the article. 
Corresponding author: Riyadh R. Al-Toma (riyadhtoma2@gmail.com)

Author roles: Al-Toma RR: Conceptualization, Data Curation, Formal Analysis, Funding Acquisition, Investigation, Methodology, Project Administration, Resources, Software, Supervision, Validation, Visualization, Writing - Original Draft Preparation, Writing - Review \& Editing

Competing interests: No competing interests were disclosed.

Grant information: The author(s) declared that no grants were involved in supporting this work.

Copyright: @ 2019 Al-Toma RR. This is an open access article distributed under the terms of the Creative Commons Attribution License, which permits unrestricted use, distribution, and reproduction in any medium, provided the original work is properly cited.

How to cite this article: Al-Toma RR. Safety and efficacy of percutaneous nephrolithotomy in patients with a single functioning kidney compared to patients with bilateral functioning kidneys [version 1; peer review: 2 approved with reservations] F1000Research 2019, 8:742 https://doi.org/10.12688/f1000research.19259.1

First published: 28 May 2019, 8:742 https://doi.org/10.12688/f1000research.19259.1 


\section{Introduction}

Urolithiasis is a frequent disorder affecting the urinary system. Globally, urinary stones are represented at a prevalence of $5-12 \%$ in males and $4-7 \%$ in females ${ }^{1}$. Percutaneous nephrolithotomy (PCNL) is the best choice for treatment of stones, giving a high stone-free rate and increased safety when compared to other techniques ${ }^{2}$. The PCNL is used for management of stones sized $2 \mathrm{~cm}^{3}$ and above ${ }^{3}$. In spite of these PCNL advantages, it is often accompanied by many complications, such as bleeding, collecting system injury, urinary leakage, infection, kidney damage and death ${ }^{4}$. Solitary kidney is defined as the condition where an individual has a single functioning kidney as compared to normally two kidneys. The incidence of stones in patients with solitary and bilateral kidneys are same rate ${ }^{5}$. The complications reported during and after PCNL of patients with solitary kidney were uncontrolled bleeding, need for angio-embolization or nephrectomy and subsequent need for kidney transplant ${ }^{6}$.

This study aimed to compare the effectiveness and safety outcomes of PCNL in patients with single functioning kidney in comparison to PCNL outcomes in patients with bilateral functioning kidneys.

\section{Methods}

Study design and setting

This study was a prospective comparative study conducted in the Urology Department of Safeer Al-Imam Al-Hussein hospital in Karbala city, Iraq, through the period from $1^{\text {st }}$ of March, 2015 to $30^{\text {th }}$ of September, 2018. We recruited patients with and without nephrostomy tubes in this study.

\section{Inclusion and exclusion criteria}

Inclusion criteria included renal stone more than $2 \mathrm{~cm}$ in size, negative culture of urine and patients with single functioning. Exclusion criteria included patients with full staghorn calculi, patients with single functioning kidney with deteriorated health, concomitant angiomyolipoma, coagulopathy diseases, collecting system perforation, severe intraoperative bleeding, elevated creatinine level and ectopic or fused kidney.

\section{Participants}

Participants were selected if they fit the aforementioned eligibility criteria and if they attended hospital. No efforts were made to control bias in recruitment or analysis. This study included a convenience sample of 173 patients (recruited face to face in the clinic and also via telephone and social media), with renal stones who underwent PCNL. Patients were arranged into two groups: group I included 51 patients with single functioning kidney and group II included 122 patients with bilateral functioning kidneys.

\section{Data sources and collections}

Assessment of patients was done by the researcher during preoperative, operative and postoperative periods. Full history and examination of patients was firstly done by the researcher and then patients were sent to the Laboratory and Radiology departments of hospital to undergo complete blood and radiological investigations. Diagnosis of renal stones was conducted by the researcher depending on clinical features, investigations and imaging techniques.

\section{Procedures}

Pre- and postoperative intravenous urography, and preoperative ultrasound and plain x-ray of the kidney were done preoperatively for all patients. PCNL surgery was initiated after giving patients general anesthesia in the lithotomy position and inserting a $6 \mathrm{~F}$ open-end ureteral catheter via cystoscopy. PCNL was conducted by a urologist and included percutaneous puncture of the pelvicalyceal system, arrangement of the tract and the fragmentation or removal of stones. At the end of the procedure, stone clearance was confirmed by endoscopy and fluoroscopy and the ureteric catheter was removed. In tubed PCNL patients, a nephrostomy tube was positioned through the Amplatz sheath and fixed to the skin and the nephrostomy was clamped for 12 hours. In tubeless PCNL, after removal of the Amplatz sheath the wound was compressed for two minutes and then sutured with one-stitch non-absorbable suture followed by dressing without insertion of a nephrostomy tube.

\section{Statistical methods}

Statistical analysis was implemented using SPSS version 20. For analysis of categorical variables, chi-square and Fisher's exact tests were applied; for continuous variables, the independent sample t-test was used. $\mathrm{P}=0.05$ was considered to indicate statistical significance.

\section{Ethical considerations}

Ethical considerations were included a written informed consent from each patient before enrolling in the study and before PCNL surgery; approval was taken from the authorities of the Safeer Al-Imam Al-Hussein hospital (code:77331).

\section{Results}

The Mean age of group I patients was 42.76 years, which was significantly higher than mean age of group II patients of 36.54 years $(\mathrm{p}=0.01)$. Male gender patients in two study groups was predominant $(52.9 \%$ vs. $53.3 \%)$; however, there was no significant difference between two study groups regarding gender $(\mathrm{p}=0.96)$ (Table 1). Postoperatively, the stone-free and residual-stone rates of group I patients were $90.2 \%$ and $9.8 \%$, respectively, while for group II patients, they were $94.3 \%$ and $5.7 \%$, respectively, with no significant difference between two study groups regarding the stone clearance $(\mathrm{p}=0.34)$. Regarding postoperative PCNL complications, no significant differences were observed between group I and group II patients in relation to postoperative bleeding $(\mathrm{p}=0.79)$ impaired renal function $(\mathrm{p}=0.84)$, organ injury $(\mathrm{p}=0.36)$ and sepsis $(\mathrm{p}=0.64)$ (Table 2). Underlying data for this study are available from Zenodo ${ }^{7}$.

\section{Discussion}

The current study showed a significant difference in mean age between patients with solitary kidneys and those with two 
Table 1. Preoperative general characteristic of patients with renal stones according to study groups.

\begin{tabular}{|c|c|c|c|c|c|}
\hline \multicolumn{2}{|c|}{ Variables } & $\begin{array}{l}\text { Single functioning } \\
\text { kidney }(\mathrm{N}=51)\end{array}$ & $\begin{array}{l}\text { Bilateral functioning } \\
\text { kidneys }(\mathrm{N}=122)\end{array}$ & $\begin{array}{c}\text { Total } \\
(\mathrm{N}=173)\end{array}$ & \multirow[t]{2}{*}{ P-value } \\
\hline & & $\mathbf{N}(\%)$ & $\mathbf{N}(\%)$ & $\mathbf{N}(\%)$ & \\
\hline \multirow[t]{2}{*}{ Gender } & Male & 27 (52.9) & 65 (53.3) & $92(53.2)$ & \multirow[t]{2}{*}{0.96} \\
\hline & Female & $24(47.1)$ & $57(46.7)$ & 81 (46.8) & \\
\hline \multicolumn{2}{|c|}{$\begin{array}{l}\text { Age, years } \\
(\text { mean } \pm S D)\end{array}$} & $42.76 \pm 14.8$ & $36.54 \pm 15.5$ & - & 0.01 \\
\hline \multicolumn{2}{|c|}{$\begin{array}{l}\text { Stone size, mm } \\
(\text { mean } \pm \mathrm{SD})\end{array}$} & $33.6 \pm 16.8$ & $32.6 \pm 14.4$ & - & 0.71 \\
\hline \multirow[t]{2}{*}{ Side } & Right & $26(51.0)$ & $55(45.1)$ & $81(46.8)$ & \multirow[t]{2}{*}{0.47} \\
\hline & Left & $25(49.0)$ & 67 (54.9) & 92 (53.2) & \\
\hline \multirow[t]{2}{*}{ Opacity } & Opaque & $36(70.6)$ & 99 (81.1) & $135(78.0)$ & \multirow[t]{2}{*}{0.12} \\
\hline & Lucent & $15(29.4)$ & 23 (18.9) & 38 (22.0) & \\
\hline \multirow[t]{2}{*}{ PCNL } & Tube & $34(66.7)$ & $77(63.1)$ & $111(64.2)$ & \multirow[t]{2}{*}{0.65} \\
\hline & Tubeless & $17(33.3)$ & 45 (36.9) & $62(35.8)$ & \\
\hline
\end{tabular}

Table 2. Postoperative outcomes of patients with renal stones according to study groups.

\begin{tabular}{|c|c|c|c|c|c|}
\hline \multicolumn{2}{|l|}{ Outcomes } & $\begin{array}{l}\text { Single functioning } \\
\text { kidney }(\mathrm{N}=51) \\
\mathrm{N}(\%)\end{array}$ & \multirow{2}{*}{$\begin{array}{l}\text { Bilateral functioning } \\
\text { kidneys }(\mathrm{N}=122) \\
\text { N (\%) }\end{array}$} & \multirow{2}{*}{$\begin{array}{c}\begin{array}{c}\text { Total } \\
(\mathrm{N}=173)\end{array} \\
\mathrm{N}(\%)\end{array}$} & \multirow[t]{2}{*}{ P-value } \\
\hline \multirow{3}{*}{ Clearance } & & & & & \\
\hline & Stone free & $46(90.2)$ & 115 (94.3) & $161(93.1)$ & \multirow[t]{2}{*}{0.34} \\
\hline & Residual & $5(9.8)$ & $7(5.7)$ & $12(6.9)$ & \\
\hline \multirow[t]{2}{*}{ Bleeding } & No transfusion & $50(98.0)$ & 119 (97.5) & $169(97.7)$ & \multirow[t]{2}{*}{0.79} \\
\hline & Need & $1(2.0)$ & $3(2.5)$ & $4(2.3)$ & \\
\hline \multirow{3}{*}{$\begin{array}{l}\text { Renal } \\
\text { functions }\end{array}$} & Stable & $50(98.0)$ & 119 (97.5) & 135 (78.0) & \multirow[t]{3}{*}{0.84} \\
\hline & Improved & $1(2.0)$ & $3(2.5)$ & 38 (22.0) & \\
\hline & Impaired & $0(0)$ & $0(0)$ & $0(0)$ & \\
\hline \multirow[t]{2}{*}{ Organ injury } & Pleural & $0(0)$ & $2(1.6)$ & $2(1.2)$ & \multirow[t]{2}{*}{0.36} \\
\hline & Bowel & $0(0)$ & $0(0)$ & $0(0)$ & \\
\hline \multicolumn{2}{|l|}{ Sepsis } & $1(2.0)$ & $4(3.3)$ & $5(2.9)$ & 0.64 \\
\hline
\end{tabular}

kidneys. The patients with single kidneys were older than those with bilateral kidneys. This finding is consistent with the results of Basiri et al. ${ }^{8}$ in Iran, which reported mean age of 42.1 years for single kidney in comparison to 38.5 years for double kidneys. No significant differences were observed between our study groups regarding gender, although the male patients were more than female patients. These findings are similar to previous Iraqi studies ${ }^{9,10}$.

The preoperative and intraoperative characteristics of both study groups patients were not significantly different. These findings agree with results of many prior studies like those of
Yaycioglu et al. ${ }^{11}$ in Turkey and Agrawal et $a l .{ }^{12}$ in India. PCNL intraoperative difficulties might be observed among patients with solitary kidney like some problems in PCNL approach and tracts $^{13}$.

Analysis of postoperative outcomes showed no significant difference in clearance rate between patients with single and bilateral kidneys $(\mathrm{p}=0.34)$. Similarly, Haberal et al. ${ }^{14}$ revealed that the postoperative stone free rate was similar for both solitary and bilateral kidneys. The postoperative complications were not significantly different between both study groups. This finding coincides with the results of Wong et $a l .{ }^{15}$ in the UK and 
Akman et al. ${ }^{16}$ in Turkey, which documented that PCNL is a safe procedure for patients with solitary kidney with acceptable complication rates.

To conclude, PCNL is effective and safe for treatment of renal stones of patients with single functioning kidney.

\section{Data availability}

Zenodo: Safety and efficacy of percutaneous nephrolithotomy. https://doi.org/10.5281/zenodo.28727787.
This project contains raw data for each patient assessed in this study.

Data are available under the terms of the Creative Commons Attribution 4.0 International license (CC-BY 4.0).

\section{Grant information}

The author(s) declared that no grants were involved in supporting this work.
1. Huang WY, Chen YF, Carter S, et al.: Epidemiology of upper urinary tract stone disease in a Taiwanese population: a nationwide, population based study. J Urol. 2013; 189(6): 2158-2163. PubMed Abstract | Publisher Full Text

2. Antonelli JA, Pearle MS: Advances in percutaneous nephrolithotomy. Urol Clin North Am. 2013; 40(1): 99-113. PubMed Abstract | Publisher Full Text

3. Mehmet NM, Ender O: Effect of urinary stone disease and its treatment on renal function. World J Nephrol. 2015; 4(2): 271-6. PubMed Abstract | Publisher Full Text | Free Full Text

4. Michel MS, Trojan L, Rassweiler JJ: Complications in percutaneous nephrolithotomy. Eur Urol. 2007; 51(4): 899-906; discussion 906. PubMed Abstract | Publisher Full Text

5. Damera R, Karthik K: Percutaneous Nephrolithotomy in Patients with Solitary Kidney- Svims Experience. IOSR Journal of Dental and Medical Sciences. 2016; 15(11): 100-103. Reference Source

6. Bucuras V, Gopalakrishnam G, Wolf JS Jr, et al: The Clinical Research Office of the Endourological Society Percutaneous Nephrolithotomy Global Study: nephrolithotomy in 189 patients with solitary kidneys. J Endourol. 2012; 26(4): 336-341.

PubMed Abstract | Publisher Full Text

7. Aaltoma R: Safety and efficacy of percutaneous nephrolithotomy in patients with sfk compared to patients with bfk. 2019 http://www.doi.org/10.5281/zenodo.2872779

8. Basiri A, Shabaninia S, Mir A, et al.: The safety and efficacy of percutaneous nephrolithotomy for management of large renal stones in single- versus double-functioning kidney patients. J Endourol. 2012; 26(3): 235-238. PubMed Abstract | Publisher Full Text

9. Al-Aridy HM: Percutaneous nephrolithotomy for renal calculi: A single surgeon experience. The Iraqi Postgraduate Medical Journal. 2013; 12(4): 573-580. Reference Source

10. Abid AF: Feasibility and Efficacy of Percutaneous Nephrolithotomy, Initial Experience. The Iraqi Postgraduate Medical Journal. 2016; 15(3): 334-337. Reference Source

11. Yaycioglu O, Egilmez T, Gul U, et al:: Percutaneous nephrolithotomy in patients with normal versus impaired renal function. Urol Res. 2007; 35(2): 101-105. PubMed Abstract | Publisher Full Text

12. Agrawal MS, Aron M, Asopa HS: Endourological renal salvage in patients with calculus nephropathy and advanced uraemia. BJU Int. 1999; 84(3): 252-256. PubMed Abstract | Publisher Full Text

13. Vicentini FC, Gomes CM, Danilovic A, et al:: Percutaneous nephrolithotomy: Current concepts. Indian J Urol. 2009; 25(1): 4-10.

PubMed Abstract | Publisher Full Text | Free Full Text

14. Haberal HB, Cıtamak B, Bozacı AC, et al.: Percutaneous Nephrolithotomy in Solitary Kidneys: 17 Years of Experience. Urology. 2017; 109: 55-59. PubMed Abstract | Publisher Full Text

15. Wong KA, Sahai A, Patel A, et al.: Is percutaneous nephrolithotomy in solitary kidneys safe? Urology. 2013; 82(5): 1013-1016. PubMed Abstract | Publisher Full Text

16. Akman T, Binbay M, Tekinarslan E, et al:: Outcomes of percutaneous nephrolithotomy in patients with solitary kidneys: a single-center experience. Urology. 2011; 78(2): 272-276.

PubMed Abstract | Publisher Full Text 


\section{Open Peer Review}

\section{Current Peer Review Status: ? ?}

\section{Version 1}

Reviewer Report 29 June 2020

https://doi.org/10.5256/f1000research.21107.r64736

(C) 2020 Barone B et al. This is an open access peer review report distributed under the terms of the Creative Commons Attribution License, which permits unrestricted use, distribution, and reproduction in any medium, provided the original work is properly cited.

\section{Biagio Barone}

Reproductive Sciences \& Odontostomatology, University of Naples, Naples, Italy

\section{Luigi Napolitano}

Reproductive Sciences \& Odontostomatology, University of Naples, Naples, Italy

The author presents a study comparing effectiveness and safety of PCNL in single functioning kidney versus both.

The study, despite does not be particularly original, could further enrich the literature on this issue.

Introduction:

"Percutaneous nephrolithotomy (PCNL) is the best choice for treatment of stones [...]" is too affirmative and absolute. Multiple articles report the use of RIRS for even larger stones size with satisfying results. It would be better to add "for stones $>2 \mathrm{~cm}$ " for example.

"The PCNL is used for management of stones sized $2 \mathrm{~cm}^{3}$ and above": refer to guidelines Methods:

"We recruited patients with and without nephrostomy tubes in this study". Move to inclusion criteria

"patients with single functioning". Define single functioning kidney (previous evaluation, solitary kidney...). How did you evaluate those kidneys? Renal scintigraphy?

"if they attended hospital": This is unnecessary as you have already defined the population recruited for the study as patients of your hospital.

Could you add further information on the surgery? (tract size, type of lithotripter, same or different surgeon). Did you use a standardized technique?

Which were the indications for tubeless PCNL? 
Which was the mean duration of postoperative follow up?

Results:

I would define the gender prevalence as slightly predominant considering the thin difference in percentages

How did you define the residual stone?

An important addition could be operative and hospitalization time, if data are available Discussion:

Enrich the discussion with more literature on the issue. Report limitations of the study and do not rush the conclusion

Is the work clearly and accurately presented and does it cite the current literature? Partly

Is the study design appropriate and is the work technically sound?

Yes

Are sufficient details of methods and analysis provided to allow replication by others? Yes

If applicable, is the statistical analysis and its interpretation appropriate? Yes

Are all the source data underlying the results available to ensure full reproducibility? Yes

Are the conclusions drawn adequately supported by the results? Partly

Competing Interests: No competing interests were disclosed.

Reviewer Expertise: Endourology - Urolithiasis

We confirm that we have read this submission and believe that we have an appropriate level of expertise to confirm that it is of an acceptable scientific standard, however we have significant reservations, as outlined above.

Reviewer Report 21 May 2020

https://doi.org/10.5256/f1000research.21107.r62595

(C) 2020 Kallidonis P. This is an open access peer review report distributed under the terms of the Creative Commons Attribution License, which permits unrestricted use, distribution, and reproduction in any medium, provided the original work is properly cited. 


\section{Panagiotis Kallidonis}

Department of Urology, University of Patras, Patras, Greece

The author is presenting a study comparing the outcome of PCNL in patients with single functioning kidneys to patients with both kidneys.

Introduction: "The PCNL is used for management of stones sized $2 \mathrm{~cm}^{3}$ and above." Please consider rephrasing. In the EAU guidelines, PCNL is the gold standard for stones $>2 \mathrm{~cm}$ (maximal diameter). Stone volume is more appropriate for reporting but most of the literature considers the maximal diameter.

Methods:

What about institutional board approval for the conducting the study? Informed consent from the patients?

"We recruited patients with and without nephrostomy tubes in this study." Should added to the inclusion-exclusion criteria.

Were the cases consecutive?

“...patients with single functioning kidney with deteriorated health." Please explain.

It is not clear which imaging studies were considered for the evaluation of the patients. CT scans are more appropriate for accurate depiction of the stone size/location.

Which was the approach for evaluating the patients with single functioning but with the presence of non-functional contralateral kidney?

Please provide a more detailed description of the technique. Was it the same for all cases? It is not clear which was the position of the patient during the PCNL (percutaneous access). What was the size of the tract?

What kind of lithotripter was used?

What was the size of the nephrostomy?

Which were the criteria for tubeless or non-tubeless technique?

I do not really understand why to clamp the nephrostomy tube for the first 12 hours. The nephrostomy tube is placed to ensure drainage not to tamponade the tract.

What was the follow-up schedule for these patients?

Which imaging techniques were used for evaluating the stone-free status and when?

Definition of stone-free status?

Clavien-classification of the complications?

Results:

A lot of information is missing. Stone location and the presence of multiple stones are important. Multitract PCNL may have been necessary, Operative time? Hospitalization time? The current information is very limited for the reader to follow the results.

Discussion:

There are several articles on PCNL and solitary kidneys that could be considered for discussion. 
Based on the experience of the author, which are important parameters for safety and efficacy of PCNL in cases with solitary kidneys? Technical points to propose?

Which are the string points of the study?

What the study adds to the available literature?

Limitations of the study?

Is the work clearly and accurately presented and does it cite the current literature? No

Is the study design appropriate and is the work technically sound?

Partly

Are sufficient details of methods and analysis provided to allow replication by others? Partly

If applicable, is the statistical analysis and its interpretation appropriate? Partly

Are all the source data underlying the results available to ensure full reproducibility? Partly

Are the conclusions drawn adequately supported by the results?

Yes

Competing Interests: No competing interests were disclosed.

Reviewer Expertise: Endourology - Urolithiaiss

I confirm that I have read this submission and believe that I have an appropriate level of expertise to confirm that it is of an acceptable scientific standard, however I have significant reservations, as outlined above. 
The benefits of publishing with F1000Research:

- Your article is published within days, with no editorial bias

- You can publish traditional articles, null/negative results, case reports, data notes and more

- The peer review process is transparent and collaborative

- Your article is indexed in PubMed after passing peer review

- Dedicated customer support at every stage

For pre-submission enquiries, contact research@f1000.com 